\title{
OS OBSTÁCULOS PARA \\ O DESENVOLVIMENTO \\ DAS POLÍTICAS PÚBLICAS \\ SOCIOAMBIENTAIS \\ URBANAS E A DEMOCRACIA PARTICIPATIVA LOCAL
}

OBSTACLES FOR THE DEVELOPMENT OF URBAN SOCIO-ENVIRONMENTAL PUBLIC POLICIES AND LOCAL PARTICIPATORY DEMOCRACY

LOS OBSTÁCULOS PARA EL DESARROLLO DE LAS POLÍTICAS PÚBLICAS SOCIOAMBIENTALES URBANAS Y LA DEMOCRACIA PARTICIPATIVA LOCAL

\section{Henrique Mioranza Koppe Pereira ${ }^{1}$ Agostinho Oli Koppe Pereira ${ }^{2}$ Cleide Calgaro ${ }^{3}$}

1 Doutor em Direito pela Universidade de Santa Cruz do Sul (UNISC) com linha de pesquisa de enfoque em políticas públicas; Pós-doutorando em Ciências Criminais pela Pontifícia Universidade Católica do Rio Grande do Sul (PUCRS). Mestre em Direito pela Universidade do Vale do Rio dos Sinos (UNISINOS); Bacharel em direito pela Universidade de Caxias do Sul (UCS); Professor no curso de graduação em Direito na UCS e pesquisador do Grupo de Pesquisa Metamorfose Jurídica - UCS. CV: http://lattes.cnpq.br/2737098416837106. E-mail: henriquekoppe@gmail.com.

2 Doutor em Direito pela Universidade do Vale do Rio dos Sinos (UNISINOS). Pós-Doutor em Direito pela Universidade do Vale do Rio dos Sinos (UNISINOS). Mestre em Direito pela Universidade Federal de Pernambuco (UFPE). Professor e pesquisador no Mestrado e Doutorado e na Graduação em Direito da Universidade de Caxias do Sul. Coordenador do Grupo de Pesquisa "Metamorfose Jurídica". CV: http://lattes.cnpq.br/5863337218571012. E-mail: Agostinho.koppe@gmail.com

3 Doutora em Ciências Sociais na Universidade do Vale do Rio dos Sinos (UNISINOS). PósDoutora em Filosofia e em Direito ambos pela Pontifícia Universidade Católica do Rio Grande do Sul (PUCRS). Doutoranda em Filosofia pela Pontifícia Universidade Católica do Rio Grande do Sul (PUCRS). Mestra em Direito e em Filosofia pela Universidade de Caxias do Sul (UCS). Atualmente é Professora e pesquisadora no Programa de Pós-Graduação - Mes- 
Resumo: No presente trabalho objetiva-se estudar a democracia participativa, seu exercício e obstáculos para o desenvolvimento de políticas públicas socioambientais voltadas ao espaço urbano. Também se analisa como se dá a participação do cidadão no espaço local. O método utilizado é o analítico. Conclui-se que a participação do cidadão no espaço local é uma das formas de se efeitvar e tornar eficaz as políticas públicas socioambientais voltadas ao meio ambiente urbano.

Palavras-chave: Meio ambiente urbano. Políticas públicas socioambientais. Democracia. Deliberação/Participação. Espaço local.

Abstract: This paper studies participatory democracy, its exercise and obstacles to the development of socio-environmental public policies focused on the urban space. It also analyzes how citizen's participation in the local space occurs. The analytical method is used. It concludes that the participation of the citizen in the local space is a way of materizlizing and making effective socio-environmental public policies focused on the urban environment.

Keywords: Urban environment. Social and environmental public policies. Democracy. Deliberation/Participation. Local space.

Resumen: El presente trabajo tiene el objetivo de estudiar la democracia participativa, su ejercicio y los obstáculos para el desarrollo de políticas públicas socioambientales dirigidas al espacio urbano. También se analiza cómo se produce la participación del ciudadano en el espacio local. Se ha utilizado el método analítico. Se concluye que la participación del ciudadano en el espacio local es una de las formas de que se efectúen y sean eficaces las políticas públicas socioambientales dirigidas al medio ambiente urbano.

Palabras clave: Medio ambiente urbano. Políticas públicas socioambientales. Democracia. Deliberación/Participación. Espacio local.

trado e Doutorado - e na Graduação em Direito da Universidade de Caxias do Sul. Pesquisadora do Grupo de Pesquisa "Metamorfose Jurídica". CV: http://lattes.cnpq.br/8547639191475261. Email: ccalgaro1@hotmail.com 


\section{INTRODUÇÃO}

7 To presente trabalho efetua-se uma análise sobre a democracia participativa voltada para o espaço local, verificando as contrariedades por ela enfrentadas quando se pretende desenvolver políticas públicas ambientais que visem à efetiva minimização dos riscos socioambientais.

Em um primeiro momento discutem-se as definições de democracia deliberativa - como uma das formas de exercício da democracia participativa -, bem como as de políticas públicas e quais os procedimentos que são realizados para que elas possam ser efetivadas na sociedade moderna contemporânea. Nesse contexto, analisa-se se as deliberações governamentais refletem os anseios do cidadão dentro de uma democracia participativa, ou se elas refletem, meramente, uma distorção dessa democracia participativa para a legitimação de decisões governamentais.

A democracia representativa faz parte do contexto em estudo, vez que, presente no Brasil, se afigura como elemento produtor de aspectos conjunturais e reprodutor de aspectos estruturais. Tanto um quanto outro, muitas vezes, trazem consigo os vícios impressos por oligarquias dominantes que se utilizam da máquina estatal para a manutenção de seu poder de mando sobre as classes menos favorecidas. Nessa seara, pretende-se analisar alguns exemplos, ocorridos no Brasil, que ilustram bem o que se afirma nesta introdução.

Outro ponto importante que se aborda neste trabalho é o disposto no item dois, ou seja, o território local brasileiro e a sua emancipação político jurídica para o gerenciamento do próprio espaço urbano. Neste aspecto, o estudo desenvolve-se sobre o espaço "local" como possibilidade de implementação da democracia participativa e, sendo assim, como elemento capaz de romper com posturas radicais que levam a intervenções estatais genéricas na atuação sobre conflitos regionais. Com este rompimento, a atuação local demandará uma postura proativa do cidadão e da comunidade para a solução dos problemas presentes no território. 
Dentro dessa ótica, trabalha-se o espaço local com o direito a um meio ambiente equilibrado, ou seja, o direito do cidadão em morar e viver em um ambiente urbano saudável que promova a qualidade da vida humana, vez que, ao se falar de políticas públicas voltadas ao meio ambiente urbano, deve-se ter em mente que atuação local pode viabilizar uma atuação governamental mais eficiente.

Como terceiro e último item a ser explorado no presente estudo, dissertase sobre o empoderamento, capital social e cidadania, visando à busca de uma atuação apropriada das políticas públicas locais com vistas a um meio ambiente equilibrado e consentâneo com a vida humana e de todos os demais espécimes. Esse empoderamento se dá através da cidadania como efetiva participação democrática do cidadão, por meio da manifestação consciente na busca de soluções aos problemas apresentados no espaço local.

O método utilizado no presente estudo foi o dialético, que possibilitou o confronto de ideias na busca de alternativas para os problemas propostos, vez que quando se abordam os temas de políticas públicas com vistas à preservação ambiental na seara da democracia, os embates se sucedem.

Espera-se que, ao final do trabalho, possa-se estabelecer parâmetros confiáveis dentro das possíveis soluções elencadas para a minimização dos problemas ambientais através de políticas públicas a serem implementadas dentro do espaço local.

\section{A DEMOCRACIA DELIBERATIVA SOBRE POLÍTICAS PÚBLICAS E O CONFLITO COM INTERESSES ENTRINCHEIRADOS}

Neste item trata-se sobre a democracia deliberativa pela qual se poderão efetuar as políticas demandadas pela população. O presente tópico apresenta os conceitos de democracia deliberativa, de políticas públicas e quais os procedimentos que são realizados para que elas possam ser efetivadas em um contexto de sociedade moderna. Com isso, será possível perceber como um governo pode atuar e como uma sociedade pode reivindicar atuações públicas, 
com foco nas políticas ambientais urbanas, em favor das necessidades dos cidadãos e como elas são aplicadas no cenário brasileiro.

Os procedimentos das deliberações democráticas são fundamentais para essa questão por possibilitarem o diálogo com o cidadão local e, principalmente, por viabilizarem uma legitimidade mais consistente do ato governamental, pois agregam à decisão o apoio direto das decisões das populações envolvidas. Rousseau ${ }^{4}$ descreve o termo deliberação como significado da própria decisão:

Conclui-se do precedente que a vontade geral é sempre certa e tende sempre à utilidade pública; donde não se segue, contudo, que as deliberações do povo tenham sempre a mesma exatidão. Deseja-se sempre o próprio bem, mas nem sempre se sabe onde ele está. Jamais se corrompe o povo, mas frequentemente o enganam e só então é que ele parece desejar o que é mau.

Sobre esse escrito, comenta Manin:

Nesta passagem as deliberações das pessoas se referem obviamente às escolhas que as pessoas fazem, e não ao processo que leva a escolhas. Não haveria sentido em dizer que o processo e moralmente justo ou não. No Discours sur l'économie politique (1755), o termo é usado da mesma maneira. Rousseau mostra como a existência de "associações parciais" prejudica a vontade geral. Ele diz "tal deliberação pode ser vantajosa para uma pequena comunidade, mas muito prejudicial para a grande comunidade" Aqui, de novo, a deliberação claramente significa decisão: esta é a decisão tomada por um grupo, que pode ser tanto benéfica para o pequeno grupo quanto prejudicial para a sociedade como um todo. ${ }^{5}$

Com isso, a deliberação constitui a escolha em si, a qual é realizada pelo indivíduo ou por uma parcela da população que decide por um bem comum a partir de seu contexto de reflexão. Sendo assim, essa decisão não se vincula, necessariamente, com uma decisão voltada ao bem comum de toda a sociedade, mas tão somente daqueles que deliberaram. Necessariamente, devem-se apresentar procedimentos equânimes para a sua realização e serem debatidos racionalmente, expõe Knight:

4 ROUSSEAU. Do contrato social. Livro II, Capítulo 3. São Paulo: Abril, 1983, p.46.

5 MANIN, Bernard. Legitimidade e deliberação política. In. WERLE, Denilson Luis; MELO, Rúrion Soares (Org.). Democracia deliberativa. São Paulo: Editora Singular, Esfera Pública, 2007, p.24. 
[...] as propostas devem ser defendidas e criticadas com razões. $O$ objetivo é articular os problemas urgentes, identificar suas soluções convenientes e exequíveis, e persuadir em vez de obrigar aqueles que possam talvez estar pensando de outro modo a reconhecer sua conveniência e exequibilidade. ${ }^{6}$

É importante esclarecer sobre as informações que os cidadãos devem ter sobre os problemas a serem resolvidos. Obviamente que, quanto maior o entendimento sobre o assunto, mais seguro estará o indivíduo sobre sua escolha, todavia o conhecimento profundo não é um pressuposto para a participação do indivíduo na deliberação democrática, pois a "deliberação tende a aumentar a informação e a localizar as preferências dos indivíduos. Isso os ajuda a descobrir aspectos das soluções propostas e de seus próprios objetivos que antes não haviam percebido"7

Esse contexto democrático implica encarar diretamente o pluralismo do século XXI, o que tende a apresentar uma sensação de insegurança, de instabilidade. $O$ desafio da pluralidade moderna não possui absolutamente nada seguro, estável, garantido, eterno e absoluto ${ }^{8}$. É importante, portanto, que se aprenda a conviver com a incerteza e com as mudanças, pois elas virão quer se esteja preparado quer não.

Com a oitiva das questões e as possíveis soluções, viabiliza-se a deliberação e elimina-se o acúmulo de discussões que impedem a tomada de decisões, porque sem elas o status quo prevalece. Para muitos conservadores, no entanto, o status quo é per se uma posição moralmente permissível e um consenso majoritário seria a única alternativa que poderia mudá-la. Sendo assim, ao encontrarem-se formações corporativas e interesses entrincheirados ${ }^{9}$, como se

6 KNIGHT, Jack; JOHSON, James. Agregação e deliberação. In. WERLE, Denilson Luis; MELO, Rúrion Soares. Democracia deliberativa. São Paulo: Editora Singulare, Esfera Pública. 2007, p.269.

7 MANIN, Bernard. Legitimidade e deliberação política. In. WERLE, Denilson Luis; MELO, Rúrion Soares (Org.). Democracia deliberativa. São Paulo: Editora Singular, Esfera Pública, 2007, p. 32.

8 BENHABIB, Seyla. Sobre um modelo deliberativo de legitimidade democrática. In. WERLE, Denilson Luis; MELO, Rúrion Soares. Democracia deliberativa. São Paulo: Editora Singulare, Esfera Pública. 2007.

9 Interesses entrincheirados são aqueles que se consolidam independentemente de debates políticos democráticos, não respeitam às discussões econômicas e sociais para proteger uma minoria oligárquica ou hegemônica. Utiliza-se esse termo exatamente por ser difícil 
sucede em muitos países da América Latina, possui-se um resultado oposto ao ideal buscado pelo pluralismo ${ }^{10}$.

Observa-se que os processos de deliberação democrática possibilitam a legitimação das decisões ${ }^{11}$, porém é fundamental que as decisões sejam realizadas a partir da democracia, para que se evite um procedimentalismo a fim de legitimar decisões, como acautela Boaventura:

Portanto, o procedimentalismo democrático não pode ser, como supõe Bobbio, um método de autorização de governos. Ele tem de ser, como nos mostra Joshua Cohen, uma forma de exercícios coletivo do poder político cuja base seja um processo livre de apresentação de razões entre iguais. Desse modo, a recuperação de um discurso argumentativo associado ao fato básico do pluralismo e às diferentes experiências é parte da reconexão entre procedimentalismo e participação ${ }^{12}$.

A deliberação não pode se tornar uma máquina procedimental para legitimar decisões governamentais, pois isso distorceria toda a fundamentalidade de democracia participativa, que tem por objetivo aproximar o cidadão da ação governamental. É abominável quando, em um Estado Democrático de Direito, a estrutura estatal passa a ser meramente procedimentalista e deixa de observar os preceitos constitucionais para legitimar interesses de oligarquias ou poderes hegemônicos, sejam esses nacionais, sejam estrangeiros. Isso ocorre quando se utiliza todo o trâmite legal e formal para aprovar uma política pública, mas se deixa de lado a aplicação das garantias constitucionais para defender interesses econômicos e progressistas ou voltados a grupos de poder.

O Poder Legislativo é o principal órgão estatal que estabelece o vínculo entre o Estado, a sociedade civil e o poder constituído. Pela legislação, faz-se

combater esse tipo de postura política, que objetiva manter benefícios para esses ícones de poder em detrimento do desenvolvimento e do avanço social.

10 NINO, Carlos Santiago. La constituición de la democracia deliberativa. Barcelona: Gedisa. 2003.

11 RECK, Janrie Rodrigues. Observações pragamático-sistêmica da personalização dos entes federativos e competências em políticas públicas. In. REIS, Jorge Renato dos; LEAL, Rogério Gesta (Org.). Direitos sociais e políticas públicas: desafios contemporâneos. Tomo 11. Santa Cruz do Sul: Edunisc, 2011.

12 SANTOS, Boaventura de Sousa; AVRITZER, Leonardo. Introdução: para ampliar o cânone democrático. In. SANTOS, Boaventura de Sousa. Democratizar a democracia: os caminhos da democracia participativa. Rio de Janeiro: Civilização Brasileira, 2002, p.53. 
presente a sociedade civil em todas as suas contradições sociais, representações e organizações. As representações do pluralismo social brasileiro são instituídas pelos eleitos (deputado e/ou senador), assim a Câmara (ou o Senado) passa a ser o local de disputa pela partilha do dinheiro público. A geração de políticas públicas parte desse processo de apropriação de verbas e destinação para os fins a que se destinam, os projetos, de acordo com as dinâmicas sociais, políticas e econômicas.

Trata-se dos representantes de movimentos sociais, de corporações econômicas nacionais e internacionais, etc. Esta correlação de forças, atuando como agentes na elaboração e instituição das políticas públicas, da qual se faz referência, sempre existiu na sociedade brasileira, mas se fortaleceu nas últimas décadas, especialmente no que se refere ao poder e força dos seus agentes originados da organização da sociedade civil. Isso porque, em anos passados, as representações da sociedade civil na esfera estatal se davam por meio das representações de classe comumente constituída por um partido político, nos dias atuais, são representações que atendem interesses específicos, de grupos econômicos, classes sociais, igrejas, movimentos sociais, ONGs, etc. ${ }^{13}$

Ocorre então uma fragmentação de interesses, individualizações de posturas, que aumentam a complexidade da deliberação democrática e, principalmente, tornam confuso o panorama político aos olhos do cidadão. Amortizando-se a participação política, diminui radicalmente a possibilidade de uma comoção popular massiva, ou até mesmo restrita a pequenas localidades.

Nas últimas décadas, assiste-se, no panorama político brasileiro, a diversos exemplos de políticas voltadas a interesses de grupos nacionais dominantes, dentre os quais, um dos mais evidentes e constantes são as políticas de amparo aos flagelados da seca do Nordeste do Brasil. As oligarquias rurais nordestinas se aproveitam da trágica situação social da localidade para captar recursos federais e os gerenciam em seu benefício, conjuntamente com os poderes administrativos locais que estão vinculados a esses poderes hegemônicos que organizam trocas de "favores" com a população para manutenção da estrutura organizacional exploradora ${ }^{14}$.

13 BONETI, Lindomar Wesler. Políticas públicas por dentro. Ijuí: Unijuí. 2006, p.55.

14 BONETI, Lindomar Wesler. Políticas públicas por dentro. Ijuí: Unijuí. 2006, p.54. 
Outro exemplo muito atual que ocorreu em território brasileiro são as obras e as normativas que foram estabelecidas para a execução da Copa do Mundo de 2014. Esse grande evento tem como interesse principal ganhos econômicos e giro financeiro que beneficiaram, principalmente, investidores estrangeiros. Para que o evento ocorresse como preconizava a FIFA, organização estrangeira e privada que estabelece normas para serem implementadas na organização das cidades-sede, que competem aos entes federativos, dentre as recomendações, salientam-se as normas de organização urbanística, de trânsito, transporte público, de habitação e remoções urbanas que retiram de suas residências irregulares populações pobres que vivem nos bairros onde estão sendo feitas as obras. Mesmo que existam políticas para a realocação dessas pessoas em outras áreas, a ação é realizada de forma arbitrária e sem a participação do cidadão. Os moradores de áreas de segregação, portanto, continuam alienados dos processos de decisões políticas que lhes dizem respeito diretamente, o que não é característico de Estado Democrático de Direito.

Os números que cercam a remoção de cidadãos para execução das obras da Copa do Mundo são bastante significativos. Para as construções do estádio do Corinthians em São Paulo, calcula-se que por volta de 5.000 famílias foram deslocadas de suas residências, o que corresponde a uma população de 25.000 pessoas ${ }^{15}$; da mesma forma, para a construção da Arena do Grêmio em Porto Alegre, foi transferida aproximadamente a mesma quantidade de pessoas. Qual é o dano social dessas remoções? Qual foi gasto aos cofres públicos para efetuar políticas de remoção e realocação dessas pessoas? Quais foram os ganhos financeiros da Copa do Mundo? Esses ganhos compensaram os danos? Essas são perguntas de alta complexidade, as quais são difíceis de responder exatamente.

Em contrapartida, as questões legais e constitucionais deixam muito mais clara e fácil a percepção do abuso da intervenção de interesses privados e estrangeiros na ordem brasileira. Não estaria, nesse caso, sendo utilizada a máquina estatal para deliberar procedimentos em favor de interesses oligárquicos e hegemônicos? O Estado tem competência constitucional para realizar esses atos de organização

15 G1. Começam as obras no estádio do Corinthians em SP. Disponível em: < http:// g1.globo.com/sao-paulo/noticia/2011/05/comecam-obras-no-estadio-do-corinthians-emsp.html>. Acesso em: 10 de abril de 2017. 
urbana a fim de garantir a melhora da qualidade de vida dos cidadãos e promover o acesso à cidade e à proteção dos direitos fundamentais do cidadão. Todavia, não é essa a motivação dessas remoções. Então, o que, na Constituição Federal, dá guarida para tal ato do Estado?

Salienta-se que, mesmo que uma política pública seja voltada ao benefício de setores públicos, pode constituir estratégias para beneficiar outros setores da sociedade como uma política de financiamento em longo prazo de maquinário e implementos agrícolas ${ }^{16}$. Essa política, se destinada aos setores agrícolas, repercutirá no fortalecimento do setor industrial e aumentará o PIB das regiões agrícolas.

Em contrapartida, no Brasil, as políticas públicas muitas vezes são direcionadas a atender interesses internacionais e reformarem a imagem do país no exterior. Assim se promovem melhorias estatísticas a fim de atingir exigências de organismos internacionais que viabilizam captação de recursos exteriores ou abrem portas a investimentos externos no país. Um exemplo, apenas para ilustrar a existência desse tipo de política pública, "é a formação superior abreviada (com a diminuição do tempo de estudos e com programação especial) de professores secundaristas municipais e estaduais especialmente em regiões mais pobres"17. Questionam-se os reais benefícios que essas políticas podem trazer à sociedade, pois, ao se observar, prioritariamente, os pré-requisitos e as imposições de ordens estrangeiras, deixam-se de lado as realidades dos territórios e as demandas populacionais presentes nas localidades. Esse exemplo demonstra que o Estado tem sacrificado a qualificação dos seus professores para poder atender exigências internacionais da quantidade mínima de professores para as regiões brasileiras. Pode-se dizer que essa política abriu portas para que se tivessem professores onde anteriormente faltavam? Claro que sim. Mas seria esse o melhor caminho para se enfrentar os problemas da educação? A resposta para essa pergunta não pode ser dada com simplicidade.

Para se evitar esse tipo de distorção do poder estatal, existem características e fases específicas para que uma política pública seja instituída e executada 16 BONETI, Lindomar Wesler. Políticas públicas por dentro. Ijuí: Unijuí. 2006, p.54. 17 BONETI, Lindomar Wesler. Políticas públicas por dentro. Ijuí: Unijuí. 2006, p.54. 
no território brasileiro. Com uma estrutura formal voltada a um movimento democrático, que defenda a soberania popular e os direitos constitucionais, pretende-se manter fortalecido o Estado Democrático de Direito. Para tanto, fazse mister a participação política dos cidadãos locais para afastar da máquina estatal interesses que não sejam verdadeiramente provenientes do povo brasileiro e de suas necessidades, assim como não sejam contrários à Constituição Federal e às normas infraconstitucionais.

Não se pode deixar de falar das recentes mobilizações populares nas ruas brasileiras que ocorreram no ano de 2013. Essas revoltas e manifestações, em busca de pressionar o governo em favor de demandas sociais, são exatamente a incidência da força política popular local que aqui se refere. Esses movimentos fortalecem a democracia local e dão legitimidade para o Estado agir em favor da população mesmo contra interesses hegemônicos e internacionais. Os rechaços dessas manifestações por parte do Estado Brasileiro, que não hesita em usar de violência policial contra os manifestantes, demonstram que o choque entre os interesses locais e os internacionais é uma realidade.

Essas distorções da democracia brasileira têm um efeito direto sobre o desenvolvimento e sobre a organização dos territórios locais. A intervenção de interesses externos, considerados hegemônicos ou de interesses vinculados a oligarquias locais, é um obstáculo para a atuação de políticas que visam ao benefício da população que ali vive. A presença de poderes extrínsecos ao país é constante no estudo quando se trata de políticas de meio ambiente urbano e de uma atuação democrática a partir do poder local.

Não há uma forma específica para dirimir os problemas que agentes globais podem ocasionar à democracia local. Não é factível propor uma maneira de eliminar possíveis malefícios advindos dos processos de globalização. Todavia, a compreensão dos processos democráticos e de como se estruturam as políticas públicas no cenário brasileiro, aliada ao estudo do empoderamento local para reforçar a cidadania da jovem democracia brasileira, é elementar para discutir os avanços das políticas urbanas para as populações excluídas, mas presentes na sociedade. 


\section{O TERRITÓRIO LOCAL E SUA EMANCIPAÇÃO POLÍTICO JURÍDICO PARA O GERENCIAMENTO DO PRÓPRIO ESPAÇO URBANO}

Neste tópico, aponta-se como o espaço local pode apresentar características e fatores para auxiliar a formação e a aplicação de políticas públicas de meio ambiente urbano e promover a democracia participativa. Ao se remeter a um território determinado, é possível salientar quais são as demandas populacionais emergentes e adequar a política para agir com mais eficiência, celeridade e economicidade. Ao agir sobre o espaço local, permite-se que o Estado dê abertura para a participação deliberativa do cidadão, que vive no território, sobre as ações, assim se fortalece a instância local como um lócus político-democrático voltado ao desenvolvimento social.

Sendo assim, em vez de se utilizar de posturas radicais em favor de uma intervenção estatal genérica para atuar sobre o conflito em diversas regiões do país, busca-se uma postura proativa do cidadão e da comunidade para a solução dos problemas presentes no território. A proposta de falar sobre empoderamento local, capital social e cidadania, portanto, trata de elementos imprescindíveis para a unificação do espaço local ${ }^{18}$. Trata-se sobre esses elementos, portanto, para entender como poderão auxiliar as políticas públicas a atenderem as necessidades sociais de acordo com os preceitos democráticos participativos. Em virtude disso, possibilita-se um diálogo entre o Estado e a sociedade a fim de afastar a dicotomia entre Direitos Sociais versus Economia que devem manter-se de forma harmônica para que conjugue o desenvolvimento econômico e o desenvolvimento social.

Cada território possui características próprias e os territórios locais se distinguem entre si a partir das comunidades que ali residem, dos seus modos de produção, acesso ou não a recursos de qualquer espécie - naturais, humanos, técnicos, financeiro, etc. Portanto, a utilização do termo território tem como intenção afirmar a concretude do espaço, que não se encontra mais em instâncias abstratas como os espaços banais globalizados, que se encontram em todo o lugar, mas em lugar nenhum ${ }^{19}$.

18 HERMANY, Ricardo. (Re)Discutindo o espaço local: uma abordagem a partir do direito social de Gurvitch. Santa Cruz do Sul: Edunisc/IPR, 2007.

19 SANTOS, Milton. Da totalidade ao Iugar. São Paulo: Edusp, 2008. 
Do outro lado dos territórios locais, estarão os espaços globais que, em contrapartida, são virtuais e atuam em universo abstrato, mas que influenciam diretamente o cotidiano dos territórios, impondo formas de organização, diretrizes de produção, de mercado, estilos de vida, de consumo de acordo com as influências políticas dos poderes hegemônicos que impõem o processo de globalização. Esse processo busca mundializar os espaços geográficos a partir de tendências técnicas, científicas e informacionais. Milton Santos aponta como características do processo de globalização dos territórios as seguintes ações:

(i) a transformação dos territórios nacionais em espaços nacionais da economia internacional; (ii) a exacerbação das especializações produtivas em nível do espaço; (iii) a concentração da produção em unidades menores, com o aumento da relação entre produto e superfície - por exemplo agricultura; (iv) a aceleração de todas as formas de circulação e seu papel crescente na regulação das atividades localizadas, com o fortalecimento da divisão territorial e da divisão social do trabalho, e a dependência deste em relação às formas espaciais e às normas sociais (jurídicas e outras) em todos os escalões; (v) a produtividade espacial como dado na escolha das localizações; o recorte horizontal e vertical dos territórios; (vi) o papel da organização e dos processos de regulação na constituição das regiões; (vii) a tensão crescente entre a localidade e a globalidade à proporção que avança o processo de globalização ${ }^{20}$.

A partir desse processo de globalização, caracterizado por essas ações, é que os fluxos que formam o espaço, as redes, criam o espaço banal ${ }^{21}$, o espaço global, o qual somente os poderes hegemônicos têm capacidade de usufruir completamente das redes e de todos os territórios. Estabelece-se, portanto, um diálogo vertical entre o território e o globo. A estruturação do território local, assim como aqueles que nele vivem, deixam de organizar-se entre si para dialogar com a lógica globalizante e toda a interação horizontal ${ }^{22}$ estará verticalizada ${ }^{23}$. O comerciante local, por exemplo, reproduzirá as tendências globais de comércio e consumo, sob pena de perder seu estabelecimento

20 SANTOS, Milton. Da totalidade ao lugar. São Paulo: Edusp, 2008, p.147.

21 Milton Santos apresenta o termo espaço banal que se refere a um espaço globalizado, desterritorializado, fragmentado, que passa a ser um espaço de todos. SANTOS, Milton. Da totalidade ao lugar. São Paulo: Edusp, 2008, p. 139.

22 A horizontalidade se refere à relação interpessoal entre os cidadãos e entre as comunidades.

23 A verticalidade se refere à interação entre os discursos globais e os territórios locais, assim como entre aqueles e os cidadãos de um território. 
para franquias multinacionais que reproduzem, impõem e ressarcem diretrizes hegemônicas de mercado. Nessa seara, desaparecem as relações aproximadas entre o comerciante e o consumidor.

Por outro lado, as horizontalidades são os domínios do cotidiano territorial, que possui tendências a criar suas próprios normas e conceitos fundados na similitude ou na complementariedade das produções e no exercício de uma existência da solidariedade". ${ }^{24}$ É exatamente nos subespaços da horizontalidade territorial onde se faz o aumento da produtividade econômica e política, por isso é importante entender qual subjetividade está a retroalimentar esses subespaços. Caso seja uma subjetividade calcada na solidariedade territorial, ter-se-á a valorização do espaço local e da cultura e, assim, os modos de produção e a organização espacial se farão de acordo com as necessidades das comunidades presentes. Se houver uma subjetividade verticalizada, encontram-se os processos de modernização e de globalização que voltam à organização espacial, aos modos de produção e à cultura para as necessidades do mercado global.

Diferentemente da organização espacial, proveniente de uma cultura territorial, os processos de globalização promovem o consumo consumptivo do espaço ${ }^{25}$. Vinculam a organização dos espaços locais a interesses e a necessidades exteriores à territorialidade a fim de maximizar os potenciais rentáveis, mesmo que isso signifique prejuízos locais como, por exemplo, danos ambientais e segregação de populações sem potencial produtivo. Da mesma forma, adapta-se aos objetos técnicos para a otimização da produção ao estabelecer normas adequadas aos interesses financeiros do mercado mundial.

Em virtude disso, existe a emergência da fortificação do espaço local, contra a fragmentação territorial e a exploração vertical dos territórios subdesenvolvidos. A tensão entre o local e o global já está instaurada. Necessita-se, portanto, de uma movimentação que revitalize o espaço local com o intuito de o território

24 SANTOS, Milton. Da totalidade ao lugar. São Paulo: Edusp, 2008, p.151.

25 Consumo consumptivo - conceito apresentado por Santos SANTOS, Milton. A urbanização brasileira. 3. ed. São Paulo: Hucitec, 1996(c). O consumo consumptivo refere-se àquele consumo que se esgota em si mesmo, diferenciando-se do consumo produtivo que se volta à produção de novos bens e serviços. SANTOS, Milton. A urbanização brasileira. 3. ed. São Paulo: Hucitec, 1996(c), p. 899. 
dialogar com o globo e combater o processo de globalização perversa ${ }^{26}$. São condições essenciais para se estabelecer uma globalização democrática e solidária especialmente no que se refere à organização espacial urbana e à preocupação com a estruturação de um ambiente urbano que promova o meio ambiente e a saúde humana, assim como cumpra com as normas e as garantias constitucionais ${ }^{27}$. Esse retorno a uma valorização territorial possibilita também o fortalecimento do próprio Direito, que volta sua atuação para demandas locais e dinamiza as decisões jurídicas em torno dos momentos econômicos e políticos para atender às exigências sociais. Assim, têm-se condições de reduzir a complexidade das demandas e diminuir o "risco de uma decisão impossível, corrupta ou ridícula diante das consequências perversas que a trivial aplicação do programa condicional do direito pode provocar nos demais sistemas" sociais ${ }^{28}$.

Aqui, pode-se trabalhar especificamente com o direito à saúde, todavia, não o direito à saúde em geral, mas ao meio ambiente urbano. Os debates por ora expostos servem para responder a alguns questionamentos acerca desse direito: Como se pode garantir a proteção dos direitos ao meio ambiente urbano, garantidos pela constituição a todos os cidadãos? Haveria a possibilidade de se realizarem políticas públicas voltadas a isso em espaços restritos ou para populações específicas do espaço local? Quais são os espaços políticos em que se dão essas questões?

Inicialmente, pode-se afirmar que o espaço local será sede da discussão dessas questões, pois, apesar de um universo globalizado, os efeitos, tanto positivos como negativos que se constituem pela eficiência das políticas públicas, incidirão diretamente em locais específicos e em uma população específica. Portanto, ao se falar de políticas públicas voltadas ao meio ambiente urbano, deve-se ter em mente que atuação local pode viabilizar uma atuação governamental mais eficiente, seja em nível nacional, regional, municipal, seja comunitário. Detectando-se um problema específico em uma determinada população, causado por situações

26 Termo utilizado por Milton Santos em Por uma outra globalização (2011) para definir como a globalização trata os países subdesenvolvidos.

27 DELORS, Jacques. O Princípio da Subsidiariedade. In: Revista Nova Cidadania, Ano II. Número 5. Cascais: Princípia, 2000.

28 SIMIONI, Rafael Lazzarotto. Direito Ambiental e Sustentabilidade. Curitiba: Juruá, 2006, p.197. 
contemporâneas ou transnacionais, pode-se atuar sobre elas a partir de ações governamentais ou comunitárias ${ }^{29}$.

Certamente, não se descarta a possibilidade de ações políticas globais, porém a proposta do presente trabalho é averiguar as possibilidades de configurações que qualifiquem as políticas urbanas locais de acordo com os devidos problemas de meio ambiente urbano. Aspira-se, com isso, evitar a espera de uma postura global para atuar em um problema eminentemente local e, assim, estimular a apresentação de novas decisões com mais celeridade quanto às demandas locais.

\section{EMPODERAMENTO, CAPITAL SOCIAL E CIDADANIA PARA UMA ATUAÇÃO ADEQUADA DAS POLÍTICAS PÚBLICAS LOCAIS DE MEIO AMBIENTE URBANO NO CONTEXTO BRASILEIRO}

Ao discutir sobre a cidadania na sociedade brasileira, questiona-se: Há possibilidade de existir cidadania plena quando há desigualdades sociais? Percebese que não há, pois se a cidadania fosse plena na efetividade, as desigualdades sociais não seriam tão marcantes e intensas e não haveria espaços de segregação. Todo brasileiro é cidadão por direito, porém a plenitude da cidadania será conferida no cotidiano do indivíduo pela articulação de direitos que permitem o reconhecimento das pessoas como indivíduos incluídos na sociedade. Segundo Hermany:

A cidadania é resultado da participação, é uma conquista da burguesia e significa a realização democrática de uma sociedade, compartilhada por todos os indivíduos, ao podente de garantir a todos o acesso ao espaço público e condições de sobrevivência digna. Exige a organização e articulação política da sociedade voltada para a realizarem de seus interesses comuns ${ }^{30}$.

Portanto, a cidadania não possui uma universalização, todavia se apresenta como uma unidade local construída pela unidade subjetiva tanto em âmbito municipal quanto no âmbito federal. Deste modo, a própria participação dos indivíduos para implementar uma forma de pensar já é um exercício de cidadania, 29 GURVITCH, Georges. Las formas de la sociabilidad. Buenos Aires: Losada, 1941.

30 HERMANY, Ricardo. O empoderamento dos setores da sociedade brasileira no plano local na busca de implementação de políticas públicas sociais. In.: HERMANY, Ricardo (Org.).

Empoderamento social local. Santa Cruz do Sul: IPR, 2010, p.80. 
assim como a participação na deliberação de interesses sociais ou, até mesmo, a atuação de acordo com a razão pública, ou seja, o próprio agir do cidadão de acordo com o pensamento constituído, democraticamente, em sua sociedade será considerado um exercício de cidadania. Para Corrêa:

A cidadania, pois, significa a realização democrática de uma sociedade, compartilhada por todos os indivíduos ao ponto de garantir a todos o acesso ao espaço público e condições de sobrevivência digna, tendo como valor-fonte a plenitude da vida. Isso exige organização e articulação política da população voltada para a superação da exclusão existente ${ }^{31}$.

A cidadania instaurou-se a partir de diversos processos de lutas e de ações proativas dos indivíduos, como é imprescindível para a consolidação de um governo representativo. Assim, para Gorczevski e Martin:

A Cidadania pressupõe democracia, liberdade de manifestação, de contestação, respeito a todos integrantes da comunidade, aos seus credos, aos seus valores, às suas culturas. Mas não somente os regimes autoritários inibem o exercício da cidadania. Mesmo nas democracias, o assistencialismo, o paternalismo e a tutela do Estado aceitos que são pela maioria das pessoas por comodismo, tampouco permitem o desenvolvimento de uma cidadania plena, porque a cidadania plena não pode dar-se ou outorgar-se, somente se alcança pela participação, pela luta e pelo empenho dos próprios indivíduos interessados. ${ }^{32}$

Para Axel Honneth, ligado à teoria do reconhecimento, a subjetividade individual é constituída por intermédio de um processo intersubjetivo. Nesse processo, a autoimagem da pessoa é o resultado não apenas de sua própria individualidade, mas das palavras e dos seus atos e dos outros. Ambos os autores interpretam os conflitos sociais como processos morais por dignidade e por respeito, e não como simples colisão entre interesses. Dessa forma, alguns críticos ligados à corrente multiculturalista salientam que não basta produzir regras universais, que vão garantir direito à educação, à saúde e à renda, mas se deve atentar para os processos simbólicos que vão produzir a negação e a estereotipização de grupos minoritários na sociedade ${ }^{33}$.

31 CORREIA, Fernando Alves. O plano Urbanístico e o Princípio da Igualdade. Coimbra: Almedina, 1989, p.217.

32 GORCZEVSKI, Clovis; MARTIN, Nuria Belloso. A necessária revisão do conceito de cidadania: movimentos sociais e novos protagonistas na esfera pública. Santa Cruz do Sul: EDUNISC, 2011, p.110.

33 SAAVEDRA, Giovani Agostini; SOBOTTKA, Emil Albert. Introdução à teoria do reconhecimento de Axel Honnet. v. 8, n. 1p. 9-18. Porto Alegre: Civitas, 2008. 
Quando se trabalha com a cidadania, esta é vista pelas duas dimensões, tanto jurídica quanto política, ou seja, juridicamente todo o brasileiro é cidadão por direito, todavia, politicamente, alguns indivíduos sofrem um processo de exclusão dessa seara. Isso não quer dizer que cidadão excluído deixa de ser cidadão, mas que esse cidadão não possui seu direito de cidadania plenamente garantido pelas políticas estatais ${ }^{34}$.

Pode-se dizer que no espaço local o cidadão vem exercer sua cidadania em um espaço físico determinado, onde vive, trabalha, relaciona-se com os demais cidadãos e exerce seus direitos civis, políticos e sociais - sociabilidadcomunión, termo utilizado por Gurvitch ${ }^{35}$. Assim, o espaço local é meio onde se faz a atuação do cidadão, por conseguinte o quanto mais participativo e maior o engajamento dos cidadãos, mais força terá a deliberação participativa, o que resultará diretamente no atendimento das demandas sociais que residirem no local, mesmo que o debate se realize em contextos mais amplos, como em Estados federativos, regiões, países ou até mesmo global.

Com isso, fica claro que a delimitação do espaço local não é algo que se restrinja apenas ao município; todavia também não é qualquer lugar sem critérios de especificidade. Assim, o espaço se dará onde acontece a prática cidadã dos indivíduos observados e os governos, ali presentes, serão os gestores responsáveis pela execução de políticas públicas adequadas para o fortalecimento da qualidade de vida dos cidadãos ${ }^{36}$.

Para que se consolide a atuação do poder local sobre problemas sociais, os quais atingem a vida dos cidadãos, é fundamental que se tenha o empoderamento

34 Desde então, e até hoje, o acordo fundamental que se plasma neste contrato social foi concretizado, tanto nos antigos como nos modernos Estados em uma Constituição. A Constituição é o resultado de uma deliberação política - quando não uma simples negociação em um momento histórico-social determinado, entre forças e valores desiguais, dentro de um amplo espaço democrático formal. Daí que o resultado de tais negociações e coerções, mais ou menos invisíveis, seja necessariamente parcial e induzido a uma ideologia, embora suficientemente válido e legítimo para fundar e dirigir um regime democrático, sancionado e, ademais, e isso é decisivo, referendado pelo povo (demos). GORCZEVSKI, Clovis; MARTIN, Nuria Belloso. A necessária revisão do conceito de cidadania: movimentos sociais e novos protagonistas na esfera pública. Santa Cruz do Sul: EDUNISC, 2011, p.77.

35 GURVITCH, Georges. Las formas de la sociabilidad. Buenos Aires: Losada, 1941.

36 HERMANY, Ricardo. (Re)Discutindo o espaço local: uma abordagem a partir do direito social de Gurvitch. Santa Cruz do Sul: Edunisc/IPR, 2007. 
social local, pois somente a partir desse elemento é que os gestores públicos serão capazes de fomentar e realizar tal política pública. O empoderamento local impulsiona os agentes a participarem de forma atuante na busca de soluções para os problemas sociais, assim, percebe-se que somente se pode falar de cidadania se houver aumento do espaço discursivo, permitindo aos indivíduos e aos grupos participarem da constituição de transformações sociais ${ }^{37}$. Esse engajamento será realizado, tanto por indivíduos singulares, a partir do voto, quanto por atores sociais governamentais ou não governamentais. Dessa forma, esses agentes, ao fomentarem o empoderamento local, possibilitam que o problema em questão seja discutido na formulação da agenda governamental.

Todo esse movimento deixa clara a desmitificação da dicotomia Estado versus Sociedade, todavia não se pode deixar de lado os possíveis conflitos gerados por grupos de interesses, que podem subordinar direta ou indiretamente atores políticos governamentais ou não governamentais, de forma decisiva, ao futuro da ação política ${ }^{38}$. O empoderamento, portanto, possui uma importância vital para o bom andamento das políticas públicas, pois quanto mais agentes sociais se engajarem na questão, mais se consolidará a vontade plural da população e mais se assegurará a justiça na decisão democrática tomada pelo governo gestor.

Quando se estabelece uma ação conjunta entre o Estado e a sociedade, os cidadãos engajam-se para levantar as necessidades de sua população. Mobilizam lideranças para buscarem os canais democráticos a fim de pressionar o poder público de acordo com os interesses da comunidade local, já que o Estado possui o interesse político para atender as demandas sociais ${ }^{39}$. É fundamental que o Estado cumpra com seu papel por intermédio de políticas públicas, pois caso não dê abertura para ouvir as lideranças comunitárias, ou não agir ativamente para que se concretizem as garantias constitucionais, estará descumprindo suas obrigações como Estado Democrático de Direito. Igualmente, apresentar-se-á,

37 HERMANY, Ricardo. O empoderamento dos setores da sociedade brasileira no plano local na busca de implementação de políticas públicas sociais. In. HERMANY, Ricardo (Org.). Empoderamento social local. Santa Cruz do Sul: IPR, 2010.

38 HERMANY, Ricardo. O empoderamento dos setores da sociedade brasileira no plano local na busca de implementação de políticas públicas sociais. In. HERMANY, Ricardo (Org.). Empoderamento social local. Santa Cruz do Sul: IPR, 2010.

39 OliVEIRA, António Cândido de. A democracia local: aspectos jurídicos. Coimbra: Coimbra Editora, 2005. 
ao cidadão, simplesmente como uma entidade opressora, que cobra impostos, utiliza-se do poder de polícia e executa leis sobre cidadãos que desconhecem qualquer benefício proveniente desse órgão autoritário e unilateral.

Portanto, o agir em parceria entre o Estado Democrático de Direito e a comunidade local se valerá do empoderamento local para reforçar a mobilidade política local e pressionar a deliberação a partir do sistema representativo. A partir disso, pode-se questionar: $O$ que poderia assegurar que realmente ocorra essa sucessão de acontecimentos? O que garante que a população se sensibilize, que os atores governamentais apoiem as reivindicações, que os grupos de pressão se voltem a favor da causa defendida pela intenção de política pública?

Nesse momento, observa-se o chamado capital social. Esse elemento "referese, a redes, normas e valores que favorecem a cooperação entre as pessoas em busca de objetivos comuns, incluindo aspectos da estrutura social e da dimensão psicológico cultural" 40 . E, continua afirmando que:

O elemento central na relação entre capital social e democracia é a comunidade cívica ou compromisso cívico. A comunidade cívica segundo Putnam (2002) se caracteriza pela existência de fortes obrigações dos cidadãos com a comunidade, expressas em intensa participação, mecanismos de igualdade política, sentimentos de solidariedade, de confiança e de tolerância, e densas redes de associações. O compromisso cívico se expressa no empenho dos cidadãos em prol de bens públicos ${ }^{41}$.

O capital social também está diretamente ligado com o sentimento de solidariedade que uma pessoa, ou um grupo, sente pelos outros e é desencadeado, mediante o uso de redes sociais ${ }^{42}$. As redes sociais são vias comunicativas de influências as quais possibilitam que as informações cheguem até os agentes sociais, para que tomem conhecimento dos argumentos e das discussões que

40 SCHMIDT, João Pedro. Os jovens e a construção de capital social no Brasil. In. BAQUERO, Marcello (Org.). Democracia, juventude e capital social no Brasil. Porto Alegre: UFRGS, 2004, p.147.

41 SCHMIDT, João Pedro. Os jovens e a construção de capital social no Brasil. In. BAQUERO, Marcello (Org.). Democracia, juventude e capital social no Brasil. Porto Alegre: UFRGS, 2004, p.149.

42 ROBISON, Lindon J.; SILES, Marcelo E.; SCHMID, A. Allan. El capital social y la reducción de la pobreza: hacia un paradigma maduro. In. ATRIA, Raúl; SILES, Marcelo (Org.). El capital social y la reducción de la pobreza en America Latina y en Caribe. Santiago de Chile: CEPAÇ, 2003. 
permeiam a população. Com isso, gera-se a preocupação coletiva, a atenção da sociedade para aquele determinado problema.

Esseelemento, portanto, éfundamentalà participação democráticaeao exercício da cidadania. Além de viabilizar informações essenciais para o engajamento, cria sentimentos de solidariedade entre os cidadãos, fomentando diretamente as reivindicações e o apoio dos grupos de pressão que, consequentemente, reforçam a participação política ativa dos cidadãos ${ }^{43}$, a mobilização dos agentes governamentais e assim sucessivamente. Pode-se dizer que o capital social é o coração das políticas públicas e da democracia, pois carrega consigo o sentimento do cidadão e bombeia a força da voz que reivindica em nome da sociedade.

Aqui se defende o empoderamento local para a execução das políticas públicas de ambiente urbano para a promoção da saúde pública através do meio ambiente, a fim de se eliminar o paternalismo dos entes federativos superiores, pois têm dificuldade para avaliar a diversidade dos municípios, assim como apresentam um tempo maior para dar respostas às necessidades da população. É nas cidades que ocorre a exclusão social, as mazelas ambientais, os problemas de saúde e os pedidos de socorro de qualquer ordem ao Estado. O contexto brasileiro é extremamente diversificado devido à sua dimensão continental e não é possível garantir a atuação plena de políticas públicas em tantas realidades diferentes. $O$ fortalecimento dos poderes locais, portanto, possibilita o aumento da eficiência estatal e a legitimidade dos governantes, o que, por consequência, fortalece a cidadania e a democracia.

O processo de urbanização imposto pelas tendências globais impele à consolidação de características que promovem a individualização do cidadão. Esse egocentrismo dissipa a consciência da cidade, afasta as pessoas umas das outras e focaliza as funções citadinas para o consumo, desestimulando o sentimento de pertencimento do cidadão com seus pares e com o local em que reside $^{44}$. O cidadão deixa de ser local para se dizer global, porém aquele que pertence a todos os lugares não pertence a lugar algum - se tudo é, nada é a existência dá-se em tempo e em espaço determinados. É claro que as novas características desenhadas no século XXI diminuem as distâncias e facilitam

43 CANOTILHO, José Joaquim Gomes. Constituição da República Portuguesa Anotada. 3. ed. Coimbra: Coimbra Editora, 1993, p.293.

44 LEFÈBVRE, Henry. O direito à cidade. São Paulo: Editora Moraes, 1991, p.17. 
a comunicação, mas de longe isso não significa que um cidadão possa ser realmente global. A fragmentação do espaço ${ }^{45}$ contribui para que se constitua uma união global, pois se destroem as diferenças e se homogeneízam os espaços, assim como se fragmentarão as culturas e o capital social para que não possam levantar-se como barreiras aos interesses do mercado global e dos poderes hegemônicos.

Esse confronto de imposição da organização espacial é evidente nos países subdesenvolvidos que são constantemente recolonizados pelo globo e essa reformatação espacial e social amortiza o capital social. O cidadão deixa de perceber a sua comunidade como o espaço em que vive e, automaticamente, se retira virtualmente dela ao se fazer ausente no local real e se fazer presente em um ideal global.

Como consequência desse processo globalizante, a deliberação democrática tomada por populações individualizadas e globalizadas, constantemente privilegia propostas que atendam às necessidades individualistas e coadunes com as diretrizes de desenvolvimento global em detrimento de propostas que correspondam diretamente com necessidades locais que auxiliariam diretamente a população local. Infelizmente, a perspectiva individualista e globalizante, que privilegia instâncias de desenvolvimento de capital, irá fortalecer a tendência de deliberar em favor de megaprojetos e afastará a possibilidade de realizar projetos que poderiam beneficiar populações locais para privilegiar projetos de desenvolvimento econômico de ordem global.

Nesse contexto, às vezes caótico, se insere a manutenção de um meio ambiente equilibrado e a possibilidade de, com isso, se ter uma sociedade saudável - física, econômica e psicologicamente. Para isso, conforme se clarifica na conclusão deste trabalho, a democracia participativa, através do empoderamento local, é, sem sombra de dúvida, uma das soluções a ser buscada para o tempo pósmoderno que se avizinha.

45 A fragmentação do espaço local é um termo utilizado por Milton Santos. SANTOS, Milton.

Por uma outra globalização. Rio de Janeiro: Record, 2011. Para se referir aos espaços que deixam de observar suas próprias características para absorver formas de estruturação espacial urbana dispostas por discursos e poderes hegemônicos. 


\section{POLÍTICAS PÚBLICAS SOCIOAMBIENTAIS URBANAS NO ESPAÇO LOCAL PARA SE EFETIVAR A DEMOCRACIA PARTICIPATIVA}

Quando se analisam os problemas ambientais no espaço urbano, verificase que os mesmos necessitam de um planejamento e de uma gestão urbana em nível local. Os municípios e as suas populações devem gerir suas mazelas socioambientais, visto que cada ente federado municipal possui a particularidade de suas problemáticas.

As mudanças sociais, nos padrões produtivos, e as dinâmicas civilizatórias levam a criação de problemas, tanto sociais como ambientais, como a questão do assentamento humano e do saneamento básico, este reconhecido pela ONU como um direito fundamental e que, nos espaços urbanos brasileiros, ainda é deficitário. Outros problemas que se apresentam são a poluição e a degradação de espaços verdes para a construção das cidades.

Verifica-se que nos países em desenvolvimento, como Brasil, a questão de institucionalização de políticas públicas, tanto sociais como ambientais, em inúmeros casos não apresenta eficácia e eficiência na sociedade. Isto acontece pelo fato de que essas políticas públicas devem ser estatais e não governamentais, ou seja, devem ser institucionalizadas como políticas de Estado e não como plataformas de governo, que ao final do mandato governista deixam de ser implementadas. Outra problemática é que essas políticas públicas devem ser amplamente discutidas e fiscalizadas em nível municipal, onde as populações das cidades podem participar e se sentir pertencentes ao espaço público em que vivem.

Essa dificuldade surge em inúmeros casos, em virtude de a incapacidade dos governantes desenvolver políticas públicas que resolvam os problemas ambientais, sociais e urbanos das cidades, além de que esses problemas descritos estão além da capacidade de serem equacionados em curto prazo nas cidades. Com isso se observa a necessidade de discussão na esfera pública, sendo que essa discussão é importante para a construção de políticas públicas socioambientais integradas, que visem atuar nos múltiplos problemas socioambientais que ocorrem nos espaços urbanos brasileiros. 
As políticas públicas devem minimizar a precarização dos espaços sociais e de sua qualidade de vida. Ao se reconhecer esse fato e se permitir que as populações locais possam participar da tomada de decisão, deliberando sobre as questões, é possível implementar um espaço para a democracia participativa. Nesse contexto deve-se salientar que se faz necessário enfrentar as dificuldades de implementação de vários direitos fundamentais, como a saúde, a educação, o transporte, o meio ambiente saudável, entre outros que devem ser efetivados e que, na prática, ainda estão longe de implementação eficaz.

Outra questão é que o poder público não deve negligenciar os bolsões de pobreza que estão inseridos nos espaços urbanos locais, vez que essa negligência, somada a crescentes problemas sociais e ambientais, levam ao aumento de riscos nas cidades. Por isso, para implementar a democracia participativa no espaço local que vise à construção de políticas públicas socioambientais, é necessário trilhar um longo caminho, onde a educação, a conscientização e o respeito com a esfera pública e populacional devem ser efetivados.

Não bastam políticas públicas socioambientais que não sejam eficientes e eficazes e, principalmente, que não possam ser implementadas porque não foram deliberadas pela população local das cidades e, por isso mesmo, não se enquadrando com os seus problemas reais da população. Assim, é necessário encontrar uma estratégia de sustentabilidade socioambiental para as cidades e seus espaços, onde uma gestão e uma redefinição de programas de ações governamentais se fazem necessárias para o bem-estar de todos.

\section{CONCLUSÕES}

A dimensões dos problemas socioambientais - danos ao meio ambiente, com consequentes danos sociais - têm tomado proporções de catástrofe no século XXI. São aspectos que repercutem no ambiente físico, mas com alcance social.

O principal propósito deste trabalho foi a busca de soluções para a manutenção de um meio ambiente equilibrado e que possibilitasse o desenvolvimento de 
uma vida humana saudável, longe das mazelas que circunscrevem um meio ambiente destruído e poluído que se encontra nas cidades. Como o foco está na possibilidade de o cidadão ter uma vida saudável, optou-se por trabalhar a democracia, como ponto de partida, para a implementação de políticas públicas com vistas à busca de soluções para a minimização dos impactos socioambientais produzidos pelas sociedades, com isso visando a um reflexo também minimizado desses impactos sobre a própria sociedade.

Inicialmente se procurou demonstrar que os conflitos oriundos das lutas pelo poder que envolvem as grandes corporações, o Estado e o próprio cidadão, demonstram o desinteresse pelo meio ambiente e, também, pelas grandes camadas da população que não possuem condições de enfrentamento com o grande capital. Nesse contexto, as decisões são tomadas longe do povo, do cidadão, que não participa ativamente das decisões e só recebe os reflexos, muitas vezes nefastos, dessas decisões.

Para dar luzes a uma saída democrática a esse problema, buscou-se concluir para a adequada configuração dos procedimentos das deliberações democráticas, que primam pelo essencial diálogo com o cidadão local e, principalmente, por viabilizarem uma legitimidade mais consistente do ato governamental, pois agregam à decisão o apoio direto das decisões das populações envolvidas, conforme se dispôs no texto. A tomada de decisões longe do cidadão local, quando se refere à implementação de políticas públicas com vistas à solução de problemas ambientais locais, se demonstra, muitas vezes, longe da realidade e produz mais problemas do que traz soluções.

Nesse diapasão, e seguindo com as análises propostas, discutiram-se, no texto, em um segundo momento, o território local e a sua emancipação política jurídica para o gerenciamento do próprio espaço urbano. Após se demonstrar o entrechoque entre o global e o local e as possíveis descaracterizações, deste último, com a implementação de políticas globais, pôde-se verificar que a visão do mercado global se volta, exclusivamente, para o lucro, desconsiderando, mais uma vez, as questões socioambientais. Os interesses globais são interesse das grandes corporações, dos grandes conglomerados econômicos que cingem a organização 
dos espaços locais a interesses exteriores com o único intuito de potencializar seus lucros, mesmo que, como se dispôs, isso signifique prejuízos locais, como danos ambientais e segregação de populações sem potencial produtivo.

Diante de tantas situações problemáticas, conclui-se pela necessidade urgente de se implementar processos democráticos participativos para a discussão das políticas públicas que visam à minimização dos danos socioambientais produzidos pelos atos humanos. A ideia de empoderamento local, com vistas à manutenção do capital social, que se perfaz na solidariedade e, consequentemente, na participação proativa do indivíduo como cidadão que se considera pertence do seu espaço local e, portanto, disposto a atuar na busca de soluções adequadas que auxiliem a obtenção de um ambiente equilibrado que proporcione uma qualidade de vida saudável a todos os espécimes que dele dependam. Por final, é de se trazer o Estado como elemento implementador das políticas públicas e que, através da democracia participava, consegue obter legitimidade e respaldo para suas ações.

\section{REFERÊNCIAS DAS FONTES CITADAS}

BENHABIB, Seyla. Sobre um modelo deliberativo de legitimidade democrática. In. WERLE, Denilson Luis; MELO, Rúrion Soares. Democracia deliberativa. São Paulo: Editora Singulare, Esfera Pública. 2007.

BONETI, Lindomar Wesler. Políticas públicas por dentro. Ijuí: Unijuí. 2006.

CANOTILHO, José Joaquim Gomes. Constituição da República Portuguesa Anotada. 3. ed. Coimbra: Coimbra Editora, 1993.

CORREIA, Fernando Alves. O plano Urbanístico e o Princípio da Igualdade. Coimbra: Almedina, 1989.

DELORS, Jacques. O Princípio da Subsidiariedade. In: Revista Nova Cidadania, Ano II. Número 5. Cascais: Princípia, 2000.

G1. Começam as obras no estádio do Corinthians em SP. Disponível em: < http://g1.globo. com/sao-paulo/noticia/2011/05/comecam-obras-no-estadio-do-corinthians-em-sp.html>. Acesso em: 10 de abril de 2017. 
GORCZEVSKI, Clovis; MARTIN, Nuria Belloso. A necessária revisão do conceito de cidadania: movimentos sociais e novos protagonistas na esfera pública. Santa Cruz do Sul: EDUNISC, 2011. GURVITCH, Georges. Las formas de la sociabilidad. Buenos Aires: Losada, 1941.

HERMANY, Ricardo. (Re)Discutindo o espaço local: uma abordagem a partir do direito social de Gurvitch. Santa Cruz do Sul: Edunisc/IPR, 2007.

HERMANY, Ricardo. (Re)Discutindo o espaço local: uma abordagem a partir do direito social de Gurvitch. Santa Cruz do Sul: Edunisc/IPR, 2007.

HERMANY, Ricardo. Município na constituição: poder local no constitucionalismo lusobrasileiro. Curitiba: Juruá, 2012.

HERMANY, Ricardo. O empoderamento dos setores da sociedade brasileira no plano local na busca de implementação de políticas públicas sociais. In. HERMANY, Ricardo (Org.). Empoderamento social local. Santa Cruz do Sul: IPR, 2010.

HERMANY, Ricardo.O empoderamento social local como pressuposto para o exercício da cidadania.In: HERMANY, Ricardo, et. al. $\mathbf{O}$ mundo da cidade e a cidade no mundo: reflexões sobre o direito local. Santa Cruz do Sul: IPR, 2009a.

KNIGHT, Jack; JOHSON, James. Agregação e deliberação. In. WERLE, Denilson Luis; MELO, Rúrion Soares. Democracia deliberativa. São Paulo: Editora Singulare, Esfera Pública. 2007

LEFÈBVRE, Henry. La presencia y la ausencia. Contribucion a la Teoria de las Representaciones. Cidade do México: Fondo de Cultura Econômica, 1983.

LEFÈBVRE, Henry. O direito à cidade. São Paulo: Editora Moraes, 1991.

MANIN, Bernard. Legitimidade e deliberação política. In. WERLE, Denilson Luis; MELO, Rúrion Soares (Org.). Democracia deliberativa. São Paulo: Editora Singular, Esfera Pública, 2007.

NINO, Carlos Santiago. La constituición de la democracia deliberativa. Barcelona: Gedisa. 2003.

OLIVEIRA, António Cândido de. A democracia local: aspectos jurídicos. Coimbra: Coimbra Editora, 2005.

RECK, Janrie Rodrigues. Observações pragamático-sistêmica da personalização dos entes federativos e competências em políticas públicas. In. REIS, Jorge Renato dos; LEAL, Rogério Gesta (Org.). Direitos sociais e políticas públicas: desafios contemporâneos. Tomo 11. Santa Cruz do Sul: Edunisc, 2011. 
ROBISON, Lindon J.; SILES, Marcelo E.; SCHMID, A. Allan. El capital social y la reducción de la pobreza: hacia un paradigma maduro. In. ATRIA, Raúl; SILES, Marcelo (Org.). El capital social y la reducción de la pobreza en America Latina y en Caribe. Santiago de Chile: CEPAÇ, 2003.

ROUSSEAU, Jean-Jacques. Discours sur l'économie politique. 1755.

ROUSSEAU. Do contrato social. Livro II, Capítulo 3. São Paulo: Abril, 1983.

SAAVEDRA, Giovani Agostini; SOBOTTKA, Emil Albert. Introdução à teoria do reconhecimento de Axel Honnet. v. 8, n. 1p. 9-18. Porto Alegre: Civitas, 2008.

SANTOS, Boaventura de Sousa. Desigualdad, Exclusión y Globalización: Hacia la Construcción Multicultural de la Igualdad y la Diferencia. Revista de Interculturalidad, p. 9-44, 2005.

SANTOS, Boaventura de Sousa. Law Against Law: Legal Reasoning in Pasargada Law. Vol.12, pp. 5 -126, Cuernavaca: Inter-cultural documentation center of Cuernavaca, 1973.

SANTOS, Boaventura de Sousa; AVRITZER, Leonardo. Introdução: para ampliar o cânone democrático. In.: SANTOS, Boaventura de Sousa. Democratizar a democracia: os caminhos da democracia participativa. Rio de Janeiro: Civilização Brasileira, 2002.

SANTOS, Boaventura de Sousa. Los nuevos movimientos sociales. Revista del Observatorio Social de América Latina/OSAL, 5, 177-188. 2001.

SANTOS, Milton. A urbanização brasileira. 3. ed. São Paulo: Hucitec, 1996(c).

SANTOS, Milton. Da totalidade ao lugar. São Paulo: Edusp, 2008.

SANTOS, Milton. Desenvolvimento econômico e urbanização em países subdesenvolvidos: os dois sistemas de fluxo da economia urbana e suas implicações espaciais. Boletim Paulista de Geografia, n. 53. São Paulo: AGB, 1977.

SANTOS, Milton. Ensaios sobre a urbanização latino-americana. São Paulo: Hucitec, 1982.

SANTOS, Milton. Espaço e sociedade. Petrópolis: Vozes, 1982.

SANTOS, Milton. Manual de Geografia urbana. São Paulo: Hucitec, 1989.

SANTOS, Milton. 0 espaço dividido. São Paulo: Edusp, 2004. 
SANTOS, Milton. O espaço do cidadão. São Paulo: Nobel, 2000.

SANTOS, Milton. Pobreza urbana. São Paulo: Hucitec, 1979.

SANTOS, Milton. Por uma outra globalização. Rio de Janeiro: Record, 2011.

SCHMIDT, João Pedro. Os jovens e a construção de capital social no Brasil. In. BAQUERO, Marcello (Org.). Democracia, juventude e capital social no Brasil. Porto Alegre: UFRGS, 2004.

SIMIONI, Rafael Lazzarotto. Direito Ambiental e Sustentabilidade. Curitiba: Juruá, 2006.

Recebido em: abr/2017

Aprovado em: mai/2017 